\title{
Left ventricular atrioventricular plane displacement: an echocardiographic technique for rapid assessment of prognosis in heart failure
}

\author{
R Willenheimer, C Cline, L Erhardt, B Israelsson
}

\begin{abstract}
Objective-To assess the prognostic value of atrioventricular plane displacement in heart failure patients.

Design-Patients were followed prospectively for one year after atrioventricular plane displacement determination.

Setting-Malmö University Hospital, with a primary catchment area of 250000 inhabitants.

Patients-181 patients with a clinical diagnosis of heart failure; age 75.7 (SD $5 \cdot 2$ ) years, duration of heart failure $2 \cdot 7$ $(5 \cdot 7)$ years; 100 men, 81 women.

Main outcome measures-Mortality in relation to atrioventricular plane displacement.

Results-Total mortality was $22 \cdot 7 \%$ (41/181), and was highly significantly (P $=0.001$ ) related to atrioventricular plane displacement. Mortality within prospectively defined categories of displacement was: $\geqslant 10.0 \mathrm{~mm}, 0 \%(0 / 19) ; 8.2$ to $9.9 \mathrm{~mm}$, $10.3 \%(3 / 29) ; 6.4$ to $8.1 \mathrm{~mm}, 19.4 \%(12 / 62)$; and $<6.4 \mathrm{~mm}, 36.6 \%$ (26/71). The groups were similar in age, sex, angiotensin converting enzyme inhibitor and $\beta$ blocker treatment, and cause and duration of heart failure.

Conclusions-Mortality in heart failure is strongly related to atrioventricular plane displacement.
\end{abstract}

(Heart 1997;78:230-236)

Keywords: atrioventricular plane displacement; echocardiography; prognosis; heart failure

The prognosis of patients with chronic heart failure is related to the degree of functional impairment of the left ventricle. ${ }^{1-5}$ Left ventricular systolic function is usually expressed as ejection fraction and is most commonly measured by radionuclide ventriculography, contrast cineangiography, or echocardiography. Echocardiography is less complicated, expensive, and time consuming than either radionuclide ventriculography or ventricular angiography. Furthermore, ventricular angiography has the disadvantage that left ventricular ejection fraction may be overestimated because of stress to the patient, or underestimated because of the negative inotropic action of the contrast medium. ${ }^{6}$

Several echocardiographic techniques can be applied to evaluate left ventricular systolic function. The fractional shortening and
Teichholz techniques are not reliable when left ventricular contraction is asymmetrical. ${ }^{7-9}$ Cross sectional echocardiography tolerates asymmetry but requires good image quality for adequate tracing of the endocardial borders, ${ }^{10-12}$ which is not always obtainable. Some investigators have reported that the limits of agreement between left ventricular ejection fraction determined by cross sectional echocardiography, on the one hand, and by radionuclide ventriculography or contrast cineangiography on the other, are quite disparate. ${ }^{1314}$ Others have shown that cross sectional echocardiography compares well with radionuclide ventriculography. ${ }^{1516}$ It has been reported that cross sectional echocardiographic assessment of regional wall motion correlates well with haemodynamic status and is reliable and reproducible. ${ }^{17}{ }^{18}$ However, it is time consuming and requires experienced investigators as well as good image quality. ${ }^{17} 18$

The left ventricular pump function has traditionally been attributed mainly to the circumferentially orientated myocardial fibres. ${ }^{19}$ However, the complexity of myocardial fibre orientation and the importance of longitudinal myocardial fibres was described in man in the early $1980 \mathrm{s.}{ }^{20}$ The significance of longitudinal fibres for left ventricular ejection has since been further emphasised. ${ }^{21-29}$ The epicardial surface of the heart remains practically immobile during the cardiac cycle, ${ }^{22}$ and normal left ventricular ejection cannot take place unless the atrioventricular plane moves. During cardiac systole the atrioventricular plane moves towards the apex as a result of contraction of longitudinal fibres, ${ }^{22}$ and during diastole it moves away from the apex. Since the distance between the apex of the heart and the chest surface is constant during the cardiac cycle, ${ }^{212230}$ the atrioventricular plane displacement measured from the surface of the thorax, using transthoracic two dimensionally guided $M$ mode echocardiography (fig 1 ), equals the intraventricular displacement. ${ }^{25}$ Left ventricular atrioventricular plane displacement determined in this way has been shown to correlate well with left ventricular ejection fraction calculated by cross sectional echocardiography using the area-length method $(r=0.96)$, left ventricular wall motion index $(r=0.91)$, radionuclide ventriculography $(r=0.82$ to $0.87)$, and contrast cineangiography $(r=$ $0 \cdot 89){ }^{26-29}$ Atrioventricular plane displacement reflects global left ventricular function despite left ventricular asymmetry, since it is determined in four different regions of the left ventricle-the septal, lateral, posterior, and 


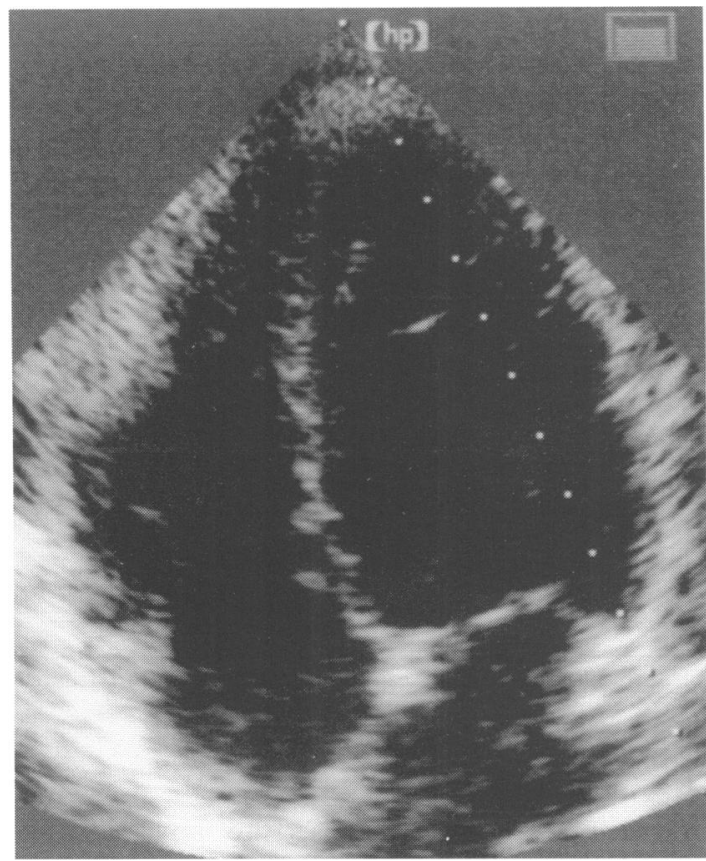

anterior regions-and since it evaluates the total shortening along the left ventricular long axis in the respective regions. It demands very little of image quality as the atrioventricular plane is highly echogenic, and the examination is rapidly performed. However, the shortening of the left ventricular long axis, that is, the shift of the atrioventricular plane, is a different expression of function in comparison with the relation between stroke volume and end diastolic volume. Indeed, the limits of agreement between left ventricular ejection fraction and atrioventricular plane displacement are not close enough for these two measurements to be interchangeable. ${ }^{26-29}$ Thus there is reason to question whether atrioventricular plane displacement provides the same prognostic information as left ventricular ejection fraction, and it is therefore imperative to evaluate the prognostic value of atrioventricular plane displacement determination before recommending that it be generally used.

The aim of this study was to investigate whether echocardiographic determination of atrioventricular plane displacement would provide prognostic information in patients with chronic heart failure, and to assess any relations between atrioventricular plane displacement and clinical findings, including medication.

\section{Methods}

PATIENTS

All patients between 65 and 84 years of age who were admitted from the emergency room at Malmö University Hospital because of symptoms suggestive of heart failure were screened for inclusion in the study between December 1991 and October 1993. Patients were considered eligible when admitted to the departments of internal medicine or cardiology with the diagnosis of heart failure, and showing at least one of the following clinical signs of heart failure: pulmonary rales, peripheral oedema, third heart sound, pulmonary congestion on chest $x$ ray. Patients were excluded if the following predefined exclusion criteria were present: follow up difficulties were foreseen (for example, patients not residing permanently in Malmö, non-Swedish speaking, reading or writing problems, drug or alcohol abuse, significant psychiatric disease, etc); concomitant serious disease that could influence morbidity and mortality; informed consent was not received; enrolment in another clinical trial; the patient's treating physician found participation unsuitable; death shortly after admission before the study echocardiographic examination could be performed. Two patients were not examined by echocardiography for administrative reasons. Eventually 181 patients were included in the study. Baseline characteristics are shown in table 1 .

\section{ECHOCARDIOGRAPHIC EXAMINATION}

A cross sectional echocardiographic examination was performed as soon after inclusion as the patient's condition allowed, by either of two investigators blinded to the results of other examinations. The equipment used was a Hewlett-Packard (Andover, Massachusetts, USA) Sonos 1000 echocardiography system and a $2.5 \mathrm{MHz}$ transducer. An apical view was obtained during silent respiration or end expiratory apnoea with the patient in a left lateral recumbent position. Left ventricular atrioventricular plane displacement was evaluated in two-dimensionally guided $M$ mode, in the four and two chamber views (fig 1). The regional displacement $(\mathrm{mm})$ was the distance covered by the atrioventricular plane between the position most remote from the apex (corresponding to the onset of contraction) and the location closest to the apex (corresponding to the end of contraction, including any postejection shortening), that is; the full extent of the displacement. It was measured in the septal, lateral, posterior, and anterior regions, and was calculated from an average of four measurements in patients with regular rhythm, 
Table 1 Baseline characteristics in relation to atrioventricular plane displacement

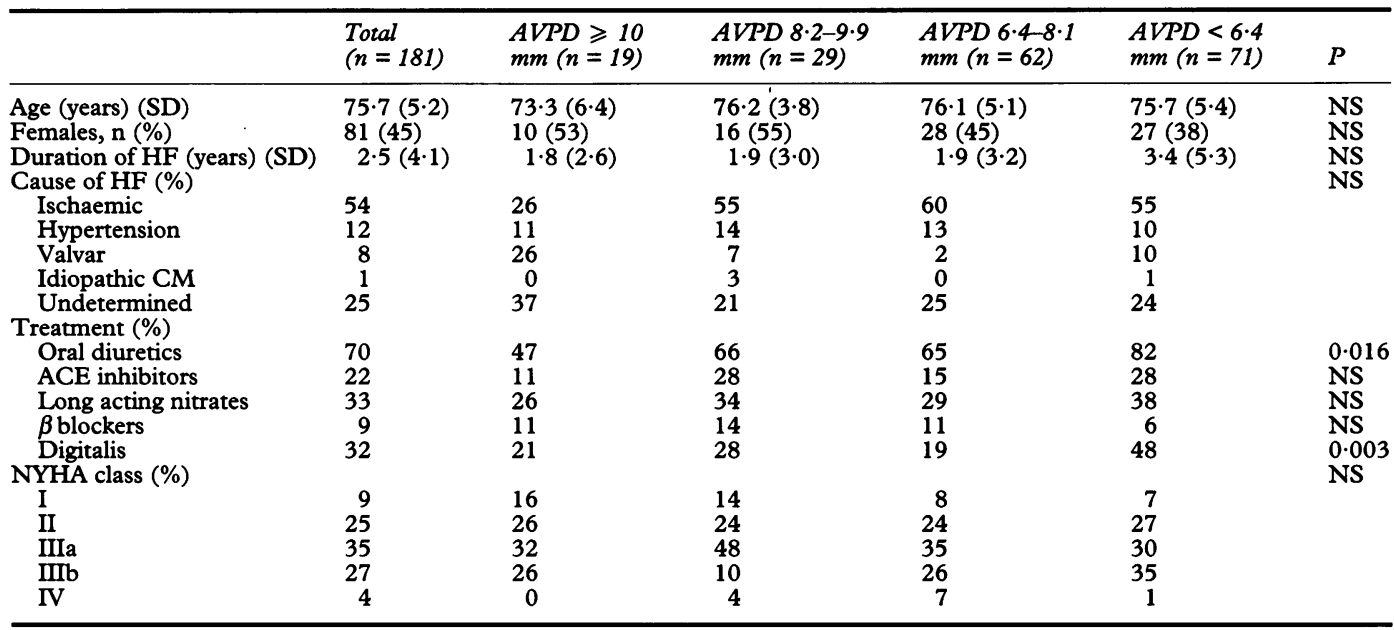

ACE, angiotensin converting enzyme; AVPD, atrioventricular plane displacement; CM, cardiomyopathy; HF, heart failure NYHA, New York Heart Association.

and eight measurements in patients with irregular rhythm. The mean of the atrioventricular plane displacement in the four regions was calculated. In our laboratory the mean interindividual variability between the two investigators in this study (examining each patient one after another) was $4.8 \%$ (atrioventricular plane displacement difference range 0 to $1.2 \mathrm{~mm}$ ) in a series of 53 consecutive patients with a mean displacement of $7.8 \mathrm{~mm}$ (range 3.3 to $15.5 \mathrm{~mm}$ ). The average time spent on a determination of atrioventricular plane displacement in our laboratory is approximately five minutes.

Left ventricular ejection fraction (LVEF) can be calculated from the regression equation, in Alam et al, ${ }^{26}$ describing the relation between the ejection fraction, determined by radionuclide ventriculography, and echocardiographically assessed atrioventricular plane displacement:

LVEF $=(5.5 \times$ mean atrioventricular plane displacement) -5

Thus the cut off values used in our study are explained: $10.0 \mathrm{~mm}=\mathrm{LVEF} \quad 0.50$; $9.1 \mathrm{~mm}=\mathrm{LVEF} \quad 0.45 ; \quad 8.2 \mathrm{~mm}=\mathrm{LVEF}$ $0.40 ; 7.3 \mathrm{~mm}=$ LVEF $0.35 ; 6.4 \mathrm{~mm}=$ LVEF 0.30 . The average atrioventricular plane displacement in elderly controls is 14.5 to $15 \mathrm{~mm}$, and a mean displacement $\geqslant 10.0 \mathrm{~mm}$ is usually considered normal. ${ }^{25} 28$

The echocardiograms were also reviewed in order to determine whether an adequate endocardial tracing in the apical view could be performed for measurement of left ventricular ejection fraction. Image quality was graded as: (1) poor, that is, less than $50 \%$ of the endocardium was visualised and no tracing could be performed; (2) mediocre, that is, $50-90 \%$ of the endocardium was visualised and a somewhat unreliable tracing could be performed; or (3) good, that is, at least $90 \%$ of the endocardium was visualised and an adequate, reliable tracing could be performed.

In order not to influence the treatment of the patients, and thereby possibly the prognosis, the results of the echocardiographic exami- nations were not disclosed to any persons involved in the care of the patients. Clinical echocardiographic examinations could be performed according to routine indications.

\section{CLINICAL ASSESSMENT}

A clinical examination was performed and noted in the patient file at entry to the emergency room. Based on the patient's history and referring to stable conditions before worsening heart failure causing admission to hospital, patients were also classified according to the New York Heart Association classification (NYHA I, II, IIIa, IIIb, or IV).

\section{FOLLOW UP}

All patients were invited to a one year clinical follow up visit. Patients not attending the follow up visit were searched for in a central database, were all deaths in our community are registered. All deaths were verified by death certificates. Mortality was thus reliably assessed.

\section{STATISTICS}

Differences between two groups regarding continuous variables were tested by the unpaired $t$ test, and for multiple group comparisons the Kruskal-Wallis test was performed. Regression analysis and analysis of variance was used to analyse correlations between two continuous variables. To assess differences between groups with respect to nominal variables the $\chi^{2}$ (for more than $2 \times 2$ ) and Fisher's exact (for $2 \times 2$ ) tests were performed. Data are expressed as mean (SD), and a $P$ value $<0.05$ was considered significant.

\section{Results}

ASSESSMENT RATE FOR ATRIOVENTRICULAR PLANE DISPLACEMENT $V$ ENDOCARDIAI

TRACING

Left ventricular atrioventricular plane displacement was readily determined in all patients. Image quality was judged to allow a completely reliable tracing of endocardial bor- 
Table 2 One year mortality in patients with an atrioventricular plane displacement (AVPD) below and above the respective cut off values

\begin{tabular}{|c|c|c|c|c|c|}
\hline \multirow[b]{2}{*}{ Cut off value ( $\mathrm{mm}$ ) } & \multicolumn{2}{|c|}{ Above cut off } & \multicolumn{2}{|c|}{ Below cut off } & \multirow[b]{2}{*}{$P$} \\
\hline & $n$ & Mortality (\%) & $n$ & Mortality (\%) & \\
\hline $\begin{array}{r}10 \cdot 0 \\
9 \cdot 1 \\
8 \cdot 2 \\
7 \cdot 3 \\
6 \cdot 4\end{array}$ & $\begin{array}{r}19 \\
31 \\
48 \\
73 \\
110\end{array}$ & $\begin{array}{c}0(0) \\
1(3 \cdot 2) \\
3(6 \cdot 2) \\
10(13 \cdot 7) \\
15(13 \cdot 6)\end{array}$ & $\begin{array}{r}162 \\
150 \\
133 \\
108 \\
71\end{array}$ & $\begin{array}{l}41(25 \cdot 3) \\
40(26 \cdot 7) \\
38(28 \cdot 6) \\
31(28 \cdot 7) \\
26(36 \cdot 6)\end{array}$ & $\begin{array}{r}0.008 \\
0.004 \\
0.001 \\
0.019 \\
<0.001\end{array}$ \\
\hline
\end{tabular}

An AVPD of $10.0 \mathrm{~mm}$ corresponds to an ejection fraction of $0.50,9 \cdot 1 \mathrm{~mm}$ to $0.45,8.2 \mathrm{~mm}$ to $0.40,7 \cdot 3 \mathrm{~mm}$ to 0.35 , and $6 \cdot 4 \mathrm{~mm}$ to $0 \cdot 30$.

ders (grade 3) for measurement of left ventricular ejection fraction in $29 / 181$ patients $(16 \%)$, permitted a suboptimal and somewhat unreliable tracing (grade 2) in $111(61 \%)$, and was too poor for tracing (grade 1 ) in 41 patients $(23 \%)$

\section{ATRIOVENTRICULAR PLANE DISPLACEMENT IN} RELATION TO MORTALITY

Mean left ventricular atrioventricular plane displacement in all patients $(n=181)$ was $7 \cdot 1$ $(2 \cdot 2) \mathrm{mm}$. It was significantly lower in the patients that died during the one year follow up ( $\mathrm{n}=41,22.7 \%)$ than in the survivors, at $5.8(1.7) \mathrm{mm} v 7.4(2.2) \mathrm{mm}, P<0.0001$. Mortality in patients with a displacement $\geqslant 10.0 \mathrm{~mm}(\mathrm{n}=19,10.5 \%)$ was $0 \%$, while it was $25.3 \%(41 / 162)$ in patients with a displacement of $<10.0 \mathrm{~mm}(P=0.008)$. The corresponding figures for the other cut off values are shown in table 2 . Thus by measuring left ventricular atrioventricular plane displacement it was possible to distinguish patients with a high as well as those with a low probability of dying during one year. Irrespective of the cut off value chosen, there was a significant difference in displacement between survivors and non-survivors (table 3 ). With decreasing atrioventricular plane displacement, mortality increased (fig 2). In patients with a displacement $\geqslant 10.0 \mathrm{~mm}$ it was $0 \%(0 / 19)$; with a displacement 8.2 to $9.9 \mathrm{~mm}$ it was $10.3 \%(3 / 29)$; with a displacement 6.4 to $8.1 \mathrm{~mm}$ it was $19.4 \%$ (12/62); and with a displacement of $<6.4 \mathrm{~mm}$ it was $36.6 \%(26 / 71)(\mathrm{P}=0.001$, fig 3 ). The four groups were similar as regards age, sex, baseline angiotensin converting enzyme (ACE) inhibitor and $\beta$ blocker treatment, and cause and duration of heart failure. There was a significant $(P=0.003)$ between group difference with respect to digitalis treatment, more patients being treated with digitalis at baseline in the group with an atrioventricular plane displacement of $<6.4$ $\mathrm{mm}$ than in the other three groups (table 1). Among the patients who survived and

Table 3 Mean atrioventricular plane displacement (AVPD) in patients with values below the respective cut off limits, comparing survivors and patients who died during one year follow up

\begin{tabular}{llllll}
\hline Cut off value & $\begin{array}{l}\text { AVPD (mm) in } \\
\text { survivors, mean }(S D)\end{array}$ & $(n)$ & $\begin{array}{l}\text { AVPD (mm) in } \\
\text { non-survivors, mean }(S D)\end{array}$ & $(n)$ & $P$ \\
\hline 10.0 & $6.8(1.6)$ & $(121)$ & $5.8(1.7)$ & $(41)$ & $<0.001$ \\
9.1 & $6.6(1.4)$ & $(110)$ & $5.7(1.6)$ & $(40)$ & 0.001 \\
8.2 & $6.2(1.3)$ & $(95)$ & $5.5(1.5)$ & $(38)$ & 0.006 \\
7.3 & $5.9(1.1)$ & $(77)$ & $5.0(1.1)$ & $(31)$ & $<0.001$ \\
6.4 & $5.2(0.9)$ & $(45)$ & $4.6(0.8)$ & $(26)$ & 0.017 \\
\hline
\end{tabular}

An AVPD of $10 \cdot 0 \mathrm{~mm}$ corresponds to an ejection fraction of $0.50,9 \cdot 1 \mathrm{~mm}$ to $0.45,8 \cdot 2 \mathrm{~mm}$ to $0 \cdot 40,7 \cdot 3 \mathrm{~mm}$ to 0.35 , and $6 \cdot 4 \mathrm{~mm}$ to $0 \cdot 30$ attended the one year control visit $(n=121)$, there were no differences between the four displacement groups with regard to treatment with ACE inhibitors (taken by $60 \%$ of the patients), $\beta$ blockers (4\%), diuretics (98\%), long acting nitrates $(38 \%)$, or digitalis $(50 \%)$.

ATRIOVENTRICULAR PLANE DISPLACEMENT IN RELATION TO CLINICAL FINDINGS AND

TREATMENT

There were no significant differences in atrioventricular plane displacement in relation to cause of heart failure (ischaemic heart disease $6.8(1.8) \mathrm{mm}$; hypertension $7.3(2.8) \mathrm{mm}$; valvar disease $8.0(3.5) \mathrm{mm}$; idiopathic cardiomyopathy $7.5(3.2) \mathrm{mm}$; undetermined 7.4 $(2 \cdot 2) \mathrm{mm}$ ), nor with regard to NYHA class (table 1).

Atrioventricular plane displacement did not differ significantly between patients treated

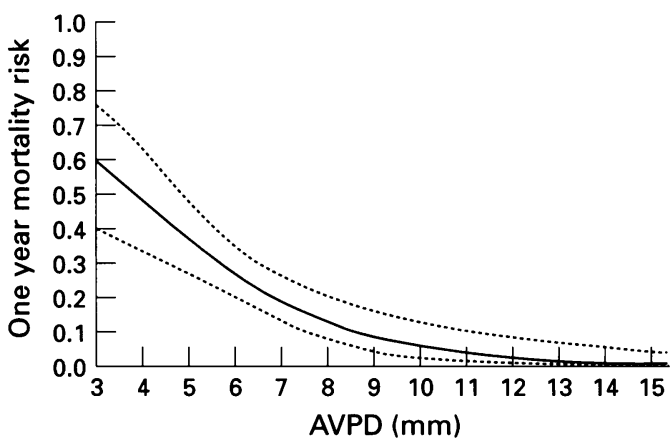

Figure 2 One year mortality risk in relation to left ventricular atrioventricular plane displacement (AVPD), by logistic regression analysis. Dotted lines show $95 \%$ confidence interval.

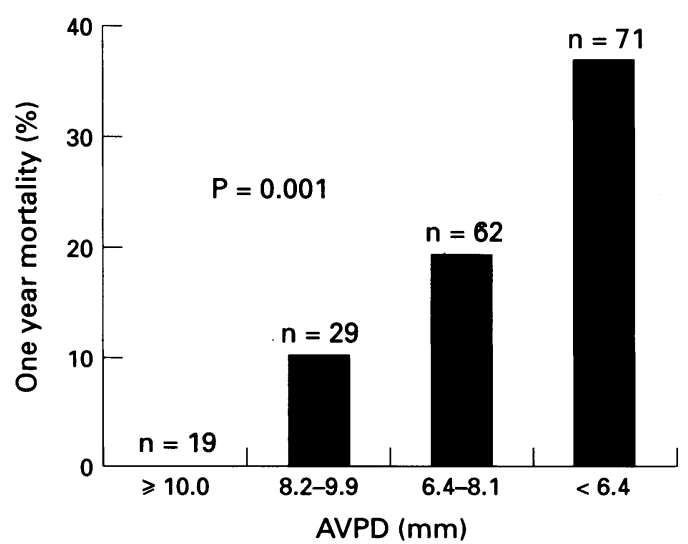

Figure 3 One year mortality in relation to left ventricular atrioventricular plane displacement (AVPD). Between group difference regarding mortality was tested by the Kruskal-Wallis test and is given in the figure. 
with an ACE inhibitor $(\mathrm{n}=39)$ and patients without ACE inhibitor treatment $(n=142)$ at baseline, or between males $(n=100)$ and females $(\mathrm{n}=81)$

None of the clinical signs pulmonary rales, dyspnoea, heart murmur, irregular heart rhythm, jugular venous distension, peripheral oedema, or peripheral cyanosis could be used to discriminate patients with respect to atrioventricular plane displacement. However, patients with a third heart sound at hospital entry $(n=8)$ had a significantly lower displacement than patients who were stated not to have a third heart sound $(n=13): 5 \cdot 8(2 \cdot 3)$ $v 7.8(1.8) \mathrm{mm}, \mathrm{P}=0.037$. In the remaining 160 patients no data were given on the presence of a third heart sound on admission; atrioventricular plane displacement did not differ significantly between these 160 patients $(7 \cdot 1(2 \cdot 3) \mathrm{mm})$ and those with a third heart sound or those with established absence of a third heart sound. There was no correlation between atrioventricular plane displacement and pulse rate on admission, but there was a weak correlation between displacement and systolic blood pressure on admission ( $r=$ $0.192, P=0.010)$. No such association was found with respect to diastolic blood pressure.

\section{Discussion}

This study shows for the first time that determination of left ventricular atrioventricular plane displacement provides strong prognostic information in heart failure patients. Mortality increased with decreasing displacement, and four of 10 patients with a displacement of less than $6.4 \mathrm{~mm}$ died within one year, while all patients with a displacement $\geqslant 10 \mathrm{~mm}$ survived. Thus determination of atrioventricular plane displacement is useful for assessment of prognosis in the individual heart failure patient, and not only in groups of patients. The results of this study are in agreement with previous findings regarding left ventricular ejection fraction and prognosis. However, our finding of a relation between atrioventricular plane displacement and prognosis is important because there was reason to question whether atrioventricular plane displacement would provide the same prognostic information as left ventricular ejection fraction. Thus atrioventricular plane displacement and left ventricular ejection fraction are quite different measurements of left ventricular function, though significantly correlated. ${ }^{26-29}$ The systolic diameter reduction in the left ventricular short axis is considered to be due to contraction of circular fibres, ${ }^{19}$ whereas the systolic left ventricular atrioventricular plane displacement has been shown to be the result of contraction of longitudinal fibres. ${ }^{22}$

Our results imply that determination of atrioventricular plane displacement may replace measurement of left ventricular ejection fraction for prognostic purposes. This could certainly save time and cost, since determination of atrioventricular plane displacement is rapidly performed (and consequently is relatively inexpensive), reproducible, rela- tively quickly mastered, and demands little of image quality in comparison with standard techniques for this purpose. In this study atrioventricular plane displacement was readily determined in all patients, whereas assessment of left ventricular ejection fraction by traditional cross sectional echocardiography (requiring an endocardial trace) would only have been completely reliable in $16 \%$ of the patients, and not possible in $23 \%$. In our laboratory we have evaluated left ventricular systolic function by determination of atrioventricular plane displacement in several thousand patients and have never failed to identify the four regions of the atrioventricular plane.

Heart failure patients require assessment of left ventricular systolic function for evaluation of prognosis and treatment selection. In Sweden alone, with almost nine million inhabitants, we estimate a yearly total of 30000 new heart failure patients ${ }^{31}$ requiring evaluation of left ventricular function; furthermore, in order to monitor the disease and evaluate treatment effects, every year a large group of the approximately 200000 pre-existing heart failure patients requires assessment of left ventricular systolic function. Such a large number of determinations is expensive, and there is need for an uncomplicated, time and cost saving, but still reliable method for this purpose. Efforts have been made to find simple and inexpensive clinical predictors of left ventricular systolic function using, for instance, electrocardiographic and patient history data. Although there are reports of successful clinical indicators of preserved or disturbed left ventricular systolic function, ${ }^{32} 33$ most have proved largely unsuccessful, especially when applied individually. ${ }^{34-40}$ Neurohormones can be used to identify groups of patients with impaired left ventricular systolic function, ${ }^{40-42}$ but for accurate determination of left ventricular ejection fraction in the individual patient an actual measurement is required. ${ }^{40}$ Furthermore, echocardiography provides important information about cardiac dimensions and valvar function, and is recommended for routine use in the correct diagnosis of heart failure by the task force on heart failure of the European Society of Cardiology. ${ }^{43}$ Since good clinical practice requires an echocardiographic examination in heart failure patients, it seems practical to evaluate left ventricular systolic function with an echocardiographic technique. Most traditional echocardiographic methods for determining left ventricular ejection fraction have disadvantages limiting their use. ${ }^{7-14}$ Recently, assessment of left ventricular function by evaluation of the regional wall motion index was proved useful in a multicentre study. ${ }^{18}$ However, this technique requires a great deal of experience for adequate interpretation, and is time consuming. Furthermore, good image quality is necessary, something that is often lacking in an elderly heart failure population, ${ }^{44} 45$ as shown in the present study. The technique of measuring atrioventricular plane displacement, however, lacks most of the disadvantages associated with traditional echocardiographic techniques, and is well 
suited for routine clinical evaluation of left ventricular function.

Assessment of left ventricular systolic function is important not only to evaluate prognosis but also to select patients with proven prognostic benefit from treatment with ACE inhibitors ${ }^{46-48}$ and $\beta$ blockers. ${ }^{49} \mathrm{~A}$ left ventricular ejection fraction of 0.35 , a cut off value commonly used in heart failure mortality studies to select patients, ${ }^{18} 464749$ corresponds to an atrioventricular plane displacement $7.3 \mathrm{~mm}$. Determination of atrioventricular plane displacement could thus be used as a simple tool to select patients who could benefit from ACE inhibitor treatment. Although one year mortality was substantially higher in our patients with an atrioventricular plane displacement $\leqslant 7.3 \mathrm{~mm}$ than in the patients in the SOLVD treatment trial (left ventricular ejection fraction $\leqslant 35),{ }^{46}$ this mortality difference does not contradict the finding that a displacement $\leqslant 7.3 \mathrm{~mm}$ selects patients at the same mortality risk as a left ventricular ejection fraction $\leqslant 0.35$. The mortality difference is presumably explained by the facts that our patients were older (mean age 76 years compared with 61 years), although similar with respect to NYHA class, and were included into the study following a period of deterioration of heart failure, whereas patients in the SOLVD study were clinically stable when included.

As with left ventricular ejection fraction, left ventricular atrioventricular plane displacement was not related to NYHA class..$^{50}$ With the exception of the presence of a third heart sound-information on which was available only in a minority of our patients-there were no associations between the various clinical assessments and atrioventricular plane displacement. This is in accordance with previous reports on the lack of an association between clinical signs of heart failure and left ventricular ejection fraction. ${ }^{51}$

\section{STUDY LIMITATIONS}

The patients in this study were included on the basis of a clinical diagnosis of heart failure. Various criteria have been used in different clinical studies. Since in order to be eligible a patient had to be judged to have heart failure by the treating physician, taking into account the whole picture of symptoms and signs of heart failure, it is unlikely that patients without heart failure were included, despite the fact that patients only had to fulfil one of the objective inclusion criteria in order to be entered into our study. Furthermore, at the one year follow up all surviving patients were still diagnosed as having heart failure by the treating cardiologist.

The mean age of our patients was 76 years, and our results may not be applicable to younger heart failure patients. However, since the majority of heart failure patients are elderly, our study population is representative of most such patients.

The difference in prognosis between the atrioventricular plane displacement groups could have been influenced by drug treatment. However, neither at baseline nor at the one year follow up visit were there any differences between displacement groups regarding treatments known to affect prognosis in heart failure, that is, ACE inhibitors and $\beta$ blockers.

\section{CONCLUSIONS}

The technique of measuring atrioventricular plane displacement is readily mastered and lacks most of the disadvantages associated with traditional echocardiographic techniques. Since atrioventricular plane displacement was closely related to mortality in heart failure patients we recommend this technique for general use. Further investigation is warranted to assess the change in atrioventricular plane displacement over time, the effects of different drugs on the displacement, and also to validate the usefulness of determining atrioventricular plane displacement in clinical practice and as a screening tool in clinical studies.

We thank Lena Öberg, Marie Holmberg, Anneli Iwarson, and Kristian Broms, without whom this study would not have been possible. The study was supported by a grant from the Swedish Heart and Lung Foundation.

1 Unverferth DV, Magorien $\mathrm{RD}$, Moeschberger ML, Baker PB, Fetters JK, Leier CV. Factors influencing the oneyear mortality of dilated cardiomyopathy. Am $\mathrm{f}$ Cardiol 1984;54:919-25.

2 Schwarz F, Mall G, Zebe H, Schmitzer E, Manthey J, Scheurlen $\mathrm{H}$, et al. Determinants of survival in patients scheurlen $\mathrm{H}$, et al. Determinants of survival in patients logic findings and left ventricular hemodynamics. Circulation 1984;54:147-52.

3 Cohn JN, Rector TS. Prognosis of congestive heart failure and predictors of mortality. Am $\mathcal{J}$ Cardiol 1988;62: and predict

4 Gradman A, Deedwania P, Cody R, Massie B, Packer M, Pitt B, et al. Predictors of total mortality and sudden death in mild to moderate heart failure: CaptoprilDigoxin Study Group. $\mathcal{f} \mathrm{Am}$ Coll Cardiol 1989;14: 564-70.

5 Costanzo MR, Augustine S, Bourge R, Bristow M, O'Connell JB, Driscoll D, et al. Selection and treatment of candidates for heart transplantation. A statement for health professionals from the committee on heart failure and cardiac transplantation of the council on clinical cardiology, American Heart Association. Circulation 1995;92:3593-612.

6 Jorgova J, Sedney MI, van der Wall EE, van Benthem A, Buis B. Comparative trial of Omnipaque 350 (iohexol) and Telebrix 350 (sodium-meglumine-ioxithalamate) in and Telebrix 350 (sodium-meglumine-ioxithalamate) in Radiol 1992;15:75-82.

7 Fortuin NJ, Hood WPJ, Sherman ME, Craige E. Determination of left ventricular volumes by ultrasound. Circulation 1971;44:575-84.

8 Teichholtz LE, Kreulen T, Herman MV, Gorim R Problems in echocardiographic volume determinations; echocardiographic-angiographic correlations in the presence or absence of asynergy. $A m \mathcal{F}$ Cardiol 1976;37:7-11.

9 Starling MR, Crawford MH, O'Rourke RA, Groves BM, Amon KW. Accuracy of subxiphoid echocardiography for assessing left ventricular size and performance. Circulation 1980;61:367-73.

10 Carr KW, Engler RL, Forsythe JR, Johnson AD, Gosink B. Measurement of left ventricular ejection fraction by mechanical cross-sectional echocardiography. Circulation 1979;59:1196-206.

11 Schiller NB, Acquatella H, Ports TA, Drew D, Goerke J, Ringertz $\mathrm{H}$, et al. Left ventricular volume from paired biplane two-dimensional echocardiography. Circulation 1979;60:547-55.

12 Parisi AF, Moynihan PF, Feldman CL, Folland ED. Approaches to determination of left ventricular volume and ejection fraction by real-time two-dimensional echocardiography. Clin Cardiol 1979;2:257-63.

13 Folland ED, Parisi AF, Moynihan PF, Jones DR, Feldman $\mathrm{CL}$, Tow DE. Assessment of left ventricular ejection fraction and volumes by real time two-dimensional fraction and volumes by real time two-d

14 Starling MR, Crawford MH, Sorenson SG, Levi B, Richards KL, O'Rourke RA. Comparative accuracy of apical biplane cross-sectional echocardiography and gated equilibrium radionuclide angiography for estimating left ventricular size and performance. Circulation 1981;63:1075-84.

15 Senior R, Sridhara BS, Basu S, Henley M, Handler CE, Raftery EB, et al. Comparison of radionuclide ventriculography and $2 \mathrm{D}$ echocardiography for the measuremen of left ventricular ejection fraction following acute myocardial infarction. Eur Heart $\mathcal{F} 1994 ; 15: 1235-9$. 16 Naik M, Diamond G, Pai T, Soffer A, Siegel R. 
Correspondence of left ventricular ejection fraction determinations from two-dimensional echocardiography, radionuclide angiography and contrast cineangiography. $千$ Am Coll Cardiol 1995;25:937-42.

17 Fisher JP, Picard MH, Mikan JS, Fram DB, Fisher JR, Kluger J, et al. Quantitation of myocardial dysfunction in ischemic heart disease by echocardiographic endocardial surface mapping: correlation with hemodynamic status. Am Heart f 1995;129:1114-21.

18 Kober L, Torp-Pedersen C, Carlsen J, Vidbaek R, Egeblad $\mathrm{H}$, on behalf of the TRACE study group. An echocardiographic method for selecting high risk patients shortly graphic method for selecting high risk patients shortly centre studies (as used in the TRACE study). Eur Heart $\mathcal{f}$ centre studies (as usec

19 Rushmer RF. Cardiovascular dynamics, 4th ed. Philadelphia: WB Saunders, 1976:93.

20 Greenbaum RA, Ho SY, Gibson DG, Becker AE, Anderson RH. Left ventricular fibre architecture in man. Br Heart $\mathcal{1} 1981 ; 45: 248-63$.

21 Jones CJH, Raposo L, Gibson DG. Functional importance of the long axis dynamics of the human left ventricle. $B$ Heart $\mathcal{f}$ 1990;63:215-20.

22 Lundbäck $S$. Cardiac pumping and the function of the ventricular septum. Acta Physiol Scand 1986;suppl 550: $1-101$

23 Pai RG, Bodenheimer MM, Pai SM, Koss JH, Adamick RD. Usefulness of systolic excursion of the mitral annulus as an index of left ventricular systolic function. $\mathrm{Am} \mathcal{F}$ Cardiol 1991;67:22-4.

24 Simonson JS, Schiller NB. Descent of the base of the left ventricle: an echocardiographic index of left ventricular ventricle: an echocardiographic index of left

25 Höglund C, Alam M, Thorstrand C. Atrioventricular valve plane displacement in healthy persons. Acta Med Scand plane displacement

26 Alam M, Höglund C. Serial echocardiographic studies following thrombolytic treatment in myocardial infarction with special reference to the atrioventricular valve plane displacement. Clin Cardiol 1992;15:30-6.

27 Alam M, Höglund C, Thorstrand C. Longitudinal systolic shortening of the left ventricle: an echocardiographic study in subjects with and without preserved global function. Clin Physiol 1992;12:443-52.

28 Alam $M$, Höglund C, Thorstrand C, Philip A Atrioventricular plane displacement in severe congestive heart failure following dilated cardiomyopathy or myocardial infarction. F Intern Med 1990;228:569-75.

29 Alam M, Höglund C, Thorstrand C, Hellekant C. Haemodynamic significance of the atrioventricular plane displacement in patients with coronary artery disease. Eur Heart $₹$ 1992;13:194-200.

30 McDonald IG. The shape and movements of the human left ventricle during systole. A study by cineangiography and by cineradiography of epicardial markers. $\mathrm{Am}$ and by cineradiography

31 Erhardt L, Caidahl K, Eriksson H, Persson H, Sylvén C. Heart failure (Hjärtsvikt). SoS rapport. Stockholm: Heart failure (Hjärtsvikt). SoS rapport. S

32 Silver MT, Rose GA Paul SD, O'Donnell CJ, O'Gara PT, Eagle KA. A clinical rule to predict preserved left ventricular ejection fraction in patients after myocardial infarction. Ann Intern Med 1994;121:750-6.

33 Rihal C, Davis K, Kennedy W, Gersh B. The utility of clinical, electrocardiographic, and roentgenographic variables in the prediction of left ventricular function. $A m \mathcal{f}$ Cardiol 1995;75:220-3.

34 DePace N, Iskandrian A, Hakki AH, Kane S, Segal B. Use of QRS scoring and Thallium-201 scintigraphy to assess left ventricular function after myocardial infarction. $A m \mathcal{F}$
Cardiol 1982;50:1262-8.

35 Palmeri S, Harrison D, Cobb F, Morris K, Harrell F, Ideker R, et al. A QRS scoring system for assessing left ventricular function after myocardial infarction. $N$ Engl $\mathcal{F}$ Med 1982;306:4-9.

36 Mattleman S, Hakki A-H, Iskandrian A, Segal B, Kane S. Reliability of bedside evaluation in determining left ventricular function: correlation with left ventricular ejection fraction determined by radionuclide ventriculography. f Am Coll Cardiol 1983;1:417-20.

37 Hamby R, Murphy D, Hoffman I. Clinical predictability of left ventricular function post myocardial infarction from the ventricular function post myocardial infarction

38 the electrocardiogram. Am Heart f 1985;109:338-42. lar ejection fraction after myocardial infarction by various lar ejection fraction after myocardial infarction by

39 Eagle K, Quertermous T, Singer D, Mulley A, Reder V, Boucher $\mathrm{C}$, et al. Left ventricular ejection fraction. Physician estimates compared with gated blood pool scan measurements. Arch Intern Med 1988;148:882-5.

40 Choy A-M, Darbar D, Lang C, Pringle T, McNeill G, Kennedy N, et al. Detection of left ventricular dysfunction after acute myocardial infarction: comparison of clinical, echocardiographic, and neurohormonal methods. Br Heart $\mathcal{f}$ 1994;72:16-22.

41 Lerman A, Gibbons R, Rodeheffer R, Bailey K, McKinley $\mathrm{L}$, Heublein $\mathrm{D}$, et al. Circulating N-terminal atrial natriuretic peptide as a marker for symptomless left-ventricular dysfunction. Lancet 1993;341:1105-9.

42 Motwani J, McAlpine H, Kennedy N, Struthers A. Plasma brain natriuretic peptide as an indicator for angiotensinconverting-enzyme inhibition after myocardial infarction. converting-enzyme inhibition

43 The Task Force on Heart Failure of the European Society of Cardiology. Guidelines for the diagnosis of heart failure. Eur Heart $\mathcal{F}$ 1995; 16:741-51.

44 Feigenbaum $H$. The value of echocardiography in older patients. Geriatrics 1975;30:106-8, 110-1.

45 Cocchi A, Zuccala G, Del Sindaco D, Alimenti M, Menichelli P, Carbonin PU. Cross-sectional echocardiography: a window on congestive heart failure in the elderly. Ageing Milano 1991;3:257-62.

46 The SOLVD investigators. Effect of enalapril on survival in patients with reduced left ventricular ejection fractions and congestive heart failure. $N$ Engl $\mathcal{F}$ Med 1991;325: 293-302.

47 The SOLVD investigators. Effect of enalapril on mortality and the development of heart failure in asymptomatic patients with reduced left ventricular ejection fractions. $N$ Engl ₹ Med 1992;327:685-91.

48 Pfeffer MA, Braunwald E, Moyé LA, Basta L, Brown EJ, Cuddy TE, et al. Effect of captopril on mortality and morbidity in patients with left ventricular dysfunction after myocardial infarction. Results of the survival and after myocardial infarction. Results of the survival and ventricula $669-77$.

49 Packer M, Bristow MR, Cohn JN, Colucci WS, Fowler MB, Gilbert EM, et al. The effect of Carvedilol on morbidity and mortality in patients with chronic heart failure. N Engl f Med 1996;334:1349-55.

50 Smith R, Johnson G, Ziesche S, Bhat G, Blankenship K, Cohn J, for the V-HeFT VA Cooperative Studies Group. Functional capacity in heart failure. Circulation 1993; 87(suppl VI):VI-88-93.

51 Gadsbøll N, Hoilund-Carlsen PF, Nielsen GG, Berning J, Brunn NE, Stage $P$, et al. Symptoms and signs of heart failure in patients with myocardial infarction: reproducibility and relationship to chest $X$-ray, radionuclide ventriculography and right heart catheterization. Eur Heart $\mathcal{F}$ 1989;10:1017-28. 